\title{
The Mechanism of Suppression of Proximal Tubular Reabsorption by Saline Infusions *
}

\author{
Floyd C. Rector, JR., $†$ Jack C. Sellman, $\$$ Manuel Martinez-Maldonado, $\S$ \\ and Donald W. Seldin with the tech nical assistance of Martha \\ Huddleston and Allen C. Nunn
}

(From the Department of Internal Medicine, The University of Texas Southwestern Medical School, Dallas, Texas)

Summary. The mechanism by which expansion of extracellular fluid volume with isotonic saline suppresses reabsorption in the proximal tubule was studied in rats by examining the relations among glomerular filtration rate (GFR), absolute and fractional reabsorption of filtrate, intrinsic reabsorptive capacity (rate of reabsorption per unit tubular volume), transit time, and tubular volume.

Saline infusions reduced the per cent of the glomerular filtrate reabsorbed in the proximal tubule from 50\% during antidiuresis to $25 \%$ during saline diuresis. The suppression of proximal reabsorption was the result of two factors: 1) a $30 \%$ reduction of intrinsic reabsorptive capacity, and 2) a $26 \%$ reduction of tubular volume per unit GFR.

GFR invariably rose during saline diuresis. However, prevention of the rise in GFR by aortic clamping had no effect on either the inhibition of intrinsic reabsorptive capacity or the reduction in tubular volume per unit GFR produced by saline infusions. Expansion of extracellular fluid volume with isotonic saline, therefore, depressed intrinsic reabsorptive capacity and tubular volume per unit GFR by some mechanism completely independent of GFR.

The effects of furosemide administration were contrasted with those of saline infusions. Furosemide inhibited intrinsic reabsorptive capacity by $40 \%$ but had no significant effect on proximal fractional reabsorption. The failure to suppress fractional reabsorption was the consequence of a disproportionate rise in tubular volume (relative to GFR) that was sufficient to completely overcome the inhibition of intrinsic reabsorptive capacity. Inhibition of intrinsic reabsorptive capacity alone, therefore, will not result in a net suppression of reabsorption of filtrate in the proximal tubule. We concluded that, although intrinsic reabsorptive capacity was inhibited during saline diuresis, the critical factor responsible for translating this inhibition into effective net suppression of proximal reabsorption was the observed reduction in tubular volume per unit GFR.

\footnotetext{
* Submitted for publication May 31, 1966; accepted September 22, 1966.

This work was supported in part by a grant from the Dallas Heart Association and in part by training grant 5 TI HE 5469-04 from the National Institutes of Health, U. S. Public Health Service.

$\dagger$ Address requests for reprints to Dr. Floyd C. Rector, Jr., Dept. of Internal Medicine, University of Texas
}

Southwestern Medical School, 5323 Harry Hines Blvd., Dallas, Texas 75235.

$\ddagger$ Work performed during the tenure of a postdoctoral fellowship of the U. S. Public Health Service, grant I-F 2-AM-28, 784-01.

$\S$ Work performed as a trainee of the U. S. Public Health Service, grant 5 TI HE 5469-04. 


\section{Introduction}

The diuresis induced by expanding extracellular fluid $(\mathrm{ECF})$ volume with isotonic saline is due in part to a decrease in the fraction of the glomerular filtrate reabsorbed in the proximal convoluted tubule $(1,2)$. However, the mechanism by which saline infusions depress fractional reabsorption in the proximal tubule has not been examined.

Previous studies in our laboratory $(3,4)$ explored the factors controlling fractional reabsorption in the proximal tubule under conditions in which glomerular filtration rate (GFR) was varied but ECF volume was kept constant. We found that the absolute rate of reabsorption during both aortic constriction and increased ureteral pressure was a direct function of tubular volume. When GFR was acutely reduced by constricting the aorta, tubular volume decreased proportionately to GFR; this resulted in a proportionate decrease in the reabsorptive rate, thereby maintaining constant fractional reabsorption. In contrast, when GFR was decreased by acutely elevating ureteral pressure, the proximal tubules dilated, and the reabsorptive rate increased proportionately; fractional reabsorption consequently rose. From these studies we concluded that reabsorption in the proximal tubule is controlled by the interaction between the intrinsic reabsorptive capacity of the tubular epithelium and some function of tubular volume. The change in the absolute rate of proximal tubular reabsorption, produced by altering GFR while maintaining ECF volume constant, is entirely the consequence of changes in tubular volume.

It is conceivable, therefore, that changes in tubular volume might also be responsible for diminished tubular reabsorption during saline diuresis. This would require that tubular volume be relatively reduced, so that at any given level of GFR tubular volume would be smaller than during antidiuresis. On the other hand, the intrinsic reabsorptive capacity might be inhibited independently of any changes in tubular volume. If reduced tubular volume were responsible for diminished proximal reabsorption during saline diuresis, intrinsic reabsorptive capacity, defined as reabsorptive rate per unit tubular volume, would be unaltered, but the reabsorptive rate over a given length of proximal tubule would be less because of the smaller tubular volume. If inhibition of the intrinsic reabsorptive capacity were the mechanism responsible for saline diuresis, reabsorptive rate per unit tubular volume would be reduced. Either of these two possibilities would result in decreased fractional reabsorption in the proximal tubule.

The present experiments were designed to examine the effects of expansion of ECF volume with isotonic saline on the intrinsic reabsorptive capacity and geometry of the proximal tubule. As shown in previous experiments (3), the relationships among reabsorptive rate, tubular volume, and GFR can be ascertained from the relation between the tubular fluid to plasma inulin ratio $\left[(\mathrm{TF} / \mathrm{P})_{\mathrm{In}}\right]$ and the time (transit time) required for fluid to pass from the glomerulus to the end of the proximal convolution. In the present studies, therefore, simultaneous measurements of $(\mathrm{TF} / \mathrm{P})_{\text {In }}$ and transit time were obtained at the end of the proximal convoluted tubule before and after the administration of isotonic saline. In addition, the relation of reabsorptive rate to tubular volume was measured directly with the shrinkingdrop technique of Gertz (5).

The results indicated that the suppression of fractional reabsorption in the proximal tubule is the consequence of both a decrease in reabsorptive rate per unit tubular volume and a relatively reduced tubular volume for any given level of GFR. Thus, both inhibition of intrinsic reabsorptive capacity and alterations of tubular geometry play a role in saline diuresis.

\section{Methods}

Studies were performed : in Sprague-Dawley rats, weighing 200 to $250 \mathrm{~g}$. To permit measurement of GFR in the micropuncture kidney by a constant infusion technique, we performed a right unilateral nephrectomy 1 to 3 weeks before the acute experiment (3). The animals were anesthetized with sodium pentobarbital and prepared for micropuncture as previously described (3). Inulin was given in a priming dose of $10 \mathrm{mg}$ and as a sustaining infusion of $2 \mathrm{mg}$ per minute to maintain a plasma concentration of approximately $100 \mathrm{mg}$ per 100 ml. Three to $5 \mathrm{ml}$ of a bicarbonate-saline solution (110 $\mathrm{mM} \mathrm{NaCl}+25 \mathrm{mM} \mathrm{NaHCO} 3$ ) was injected intravenously to replace the loss of extracellular fluid occurring during the surgical preparation for micropuncture. During control periods the bicarbonate-saline solution was infused at a rate of $0.02 \mathrm{ml}$ per minute. After completion of three control periods, saline diuresis was induced by infusing the bicarbonate-saline solution at a rate of 0.4 
$\mathrm{ml}$ per minute. The infusion was continued for 1 hour before collecting samples for the diuretic periods.

In the first group of six rats samples of tubular fluid were collected for inulin analysis from the end of the proximal convolution, which was located by observing the passage of Lissamine green through the proximal tubule as described by Gertz, Mangos, Braun, and Pagel (6). With this technique all tubular punctures have been found to be located between 55 and $65 \%$ of the total length of the proximal tubule when the tubules were injected with latex and microdissected. In association with each collection of tubular fluid the transit time to the puncture site was measured with Lissamine green as previously described (3). In each rat four to eight samples were collected during control periods and a similar number during periods of saline diuresis.

In a second group of 18 rats the intrinsic reabsorptive capacity was measured with the shrinking-drop technique $(4,5)$. The animals were treated in precisely the same manner as in the first set of experiments. In addition, however, five of the rats were given $5 \mathrm{mg}$ deoxycorticosterone acetate (DOCA) in oil intramuscularly for 2 days before and on the morning before the experiment. In three of the rats intrinsic reabsorptive capacity and transit time were measured during saline diuresis before and after reduction of the GFR. The GFR was reduced by constricting the aorta above the renal arteries as previously described (3). In each rat 10 to 15 measurements were made during control periods and 15 to 20 during periods of saline diuresis.

In a third group of seven rats the effect of furosemide (25 $\mathrm{mg}$ per $\mathrm{kg}$ body weight intravenously) on $(\mathrm{TF} / \mathrm{P})_{\text {In }}$ and transit time was determined. Transit time was measured, and samples of tubular fluid were collected in the same rat before and after the administration of furosemide. To prevent depletion of the ECF volume during the diuretic periods, we measured the volume of urine at 1-minute intervals and immediately replaced it by infusing equal volumes of the bicarbonate-saline solution. In a fourth group of five rats the intrinsic reabsorptive capacity was measured with the shrinking-drop technique before and after administration of furosemide (25 $\mathrm{mg}$ per $\mathrm{kg}$ ).

In one or two rats from each group changes in tubular size were determined by photographing the same microscopic field on the surface of the kidney during control and experimental periods. Maximal contrast was achieved by photographing the surface while Lissamine green was passing through the tubules. The negatives were projected onto white paper and the outlines of the tubules traced. The tracings were then cut out and weighed. The ratio of the control to experimental weights for each tubular tracing is proportional to the ratio of the radii, and the square of the ratio of the weights is proportional to the ratio of the tubular volumes (3). Although this method does not give an absolute value for tubular volume, it does yield an accurate estimate of the degree of change in tubular volume during different conditions.
The concentration of inulin in tubular fluid was measured with the microanthrone method of Hilger, Klümper, and Ullrich (7) as modified by Dirks, Cirksena, and Berliner (1). Inulin in plasma filtrate and urine was measured by the anthrone method (8). Lissamine green was found not to interfere with the determination of inulin. Plasma solids were measured by refractometry, and all plasma inulin concentrations were corrected for plasma water. Sodium in plasma and urine was measured by flame photometry with lithium as an internal standard.

Calculations. Fractional reabsorption was calculated from the $(T F / P)_{\text {In }}$ ratio with the expression,

$$
\text { fractional reabsorption }=\left[1-(P / T F)_{1 n}\right] \text {. }
$$

In previous studies on the mechanism of glomerulotubular balance $(3,4)$, it was shown that, as originally suggested by Gertz $(5,6)$, fractional reabsorption in the proximal convoluted tubule can be described by two expressions : and

$$
\text { fractional reabsorption }=\left(C / \pi r^{2}\right) \quad\left(\pi r^{2} d / V o\right),
$$

$$
\log (\mathrm{TF} / \mathrm{P})_{\mathrm{In}}=\mathrm{CT} / 2.3 \pi \mathrm{r}^{2},
$$

where $\mathrm{C}$ is the reabsorptive rate constant per unit tubular length, $r$ is the tubular radius, Vo is GFR per nephron, $\mathrm{d}$ is tubular length, and $\mathrm{T}$ is the time (transit time) required for fluid to pass from the glomerulus to point $d$ in the tubule.

In previous studies when ECF volume was kept constant, C was found to vary proportionately to the square of the tubular radius; consequently, under any given set of circumstances $\mathrm{C} / \pi \mathrm{r}^{2}$ can be considered a constant and by definition is the intrinsic reabsorptive capacity, expressed as volume reabsorbed per unit time per unit tubular volume. The value for $\mathrm{C} / \pi \mathrm{r}^{2}$ is determined in two ways. In the first method $\mathrm{C} / \pi \mathrm{r}^{2}$ is calculated from the simultaneously measured transit time and $(T F / P)_{\text {In, }}$ with Equation 3. In the second method the shrinkingdrop technique is used, and the intrinsic reabsorptive capacity is then calculated from the expression,

$$
\mathrm{C} / \pi \mathrm{r}^{2}=0.693 / \mathrm{t}_{\frac{1}{2}},
$$

where $t_{i}$ is the time required to reabsorb $50 \%$ of the injected column of saline from the tubular lumen.

The value for the ratio of the tubular volume to the GFR per nephron, ( $\left.\pi r^{2} \mathrm{~d} / \mathrm{Vo}\right)$, was estimated by inserting the value for $C / \pi r^{2}$ (calculated from the transit time and inulin ratio, with Equation 3) into Equation 2.

\section{Results}

The results of six complete studies are summarized in Table I. The excretion of sodium, which ranged from 0.3 to $2.0 \%$ of the filtered sodium during control periods, rose sharply during the infusion of saline, reaching values ranging from 7 to $20 \%$ of the filtered sodium. In every experiment there was an increase in GFR during 
TABLE I

Effect of saline infusions on transit time and reabsorption in the proximal convoluted tubule

\begin{tabular}{|c|c|c|c|c|c|c|c|c|c|c|c|c|}
\hline \multirow[b]{2}{*}{ Rat no. } & \multicolumn{2}{|c|}{$\begin{array}{l}\text { Sodium ex- } \\
\text { cretion } \\
\text { (\% of filtered) }\end{array}$} & \multicolumn{3}{|c|}{ GFR* } & \multicolumn{2}{|c|}{ Transit time } & \multicolumn{2}{|c|}{$(\mathrm{TF} / \mathrm{P})_{\mathrm{In}} \dagger$} & \multicolumn{3}{|c|}{ Per cent reabsorption $\dagger$} \\
\hline & Control & $\overline{\text { Saline }}$ & Control & Saline & Change & Control & $\overline{\text { Saline }}$ & Control & Saline & Control & Saline & Change \\
\hline & $\%$ & $\% n$ & $\mathrm{ml} / \mathrm{min} / \mathrm{kg}$ & $\mathrm{ml} / \mathrm{min} / \mathrm{kg}$ & $\%$ & sec & $\mathrm{sec}$ & & & $\%$ & $\%$ & $\%$ \\
\hline 1 & 0.7 & 11 & 5.2 & 8.8 & $\begin{array}{r}+69 \\
\end{array}$ & $\begin{array}{r}15.2 \\
+0.5\end{array}$ & $\begin{array}{r}8.7 \\
+0.5\end{array}$ & $\begin{array}{r}2.18 \\
+0.16\end{array}$ & $\begin{array}{r}1.29 \\
+0.07\end{array}$ & $\begin{array}{r}53 \\
+3\end{array}$ & $\begin{array}{r}21 \\
+4\end{array}$ & -60 \\
\hline 2 & 0.3 & 14 & 6.6 & 9.1 & +38 & $\begin{array}{r}12.5 \\
\pm 0.9\end{array}$ & $\begin{array}{r}6.3 \\
+0.2\end{array}$ & $\begin{array}{r}2.33 \\
\pm 0.21\end{array}$ & $\begin{array}{r}1.47 \\
\pm 0.04\end{array}$ & $\begin{array}{r}55 \\
55 \\
\pm 4\end{array}$ & $\begin{array}{r}14 \\
31 \\
\pm 2\end{array}$ & -44 \\
\hline 3 & 1.5 & 14 & 6.1 & 7.1 & +16 & $\begin{array}{r}11.9 \\
+0.4\end{array}$ & $\begin{array}{r}9.0 \\
+0.8\end{array}$ & $\begin{array}{r}2.20 \\
+0.06\end{array}$ & $\begin{array}{r}1.47 \\
+0.08\end{array}$ & $\begin{array}{r}54 \\
+1\end{array}$ & $\begin{array}{r}31 \\
+3\end{array}$ & -43 \\
\hline 4 & 2.0 & 7 & 8.9 & 9.5 & +7 & $\begin{array}{r}7.9 \\
+0.8\end{array}$ & $\begin{array}{r}5.0 \\
+0.4\end{array}$ & $\begin{array}{r}1.46 \\
+0.07\end{array}$ & $\begin{array}{r}1.19 \\
+0.04\end{array}$ & $\begin{array}{r}31 \\
+4\end{array}$ & $\begin{array}{r}16 \\
+2\end{array}$ & -48 \\
\hline 5 & 1.4 & 11 & 9.2 & 11.6 & +26 & $\begin{array}{r}9.2 \\
+0.6\end{array}$ & $\begin{array}{r}6.2 \\
+0.4\end{array}$ & $\begin{array}{r}1.84 \\
+0.02\end{array}$ & $\begin{array}{r}1.26 \\
+0.02\end{array}$ & $\begin{array}{r}46 \\
+1\end{array}$ & $\begin{array}{r}20 \\
+1\end{array}$ & -56 \\
\hline 6 & 0.7 & 20 & 6.0 & 8.2 & +37 & $\begin{array}{r}13.6 \\
\pm 1.4\end{array}$ & $\begin{array}{r}7.7 \\
\pm 0.4\end{array}$ & $\begin{array}{r}2.08 \\
\pm 0.11\end{array}$ & $\begin{array}{r}1.30 \\
\pm 0.06\end{array}$ & $\begin{array}{r}51 \\
\pm 2\end{array}$ & $\begin{array}{r}22 \\
\pm 3\end{array}$ & -57 \\
\hline Average & & & & & +32 & 11.7 & 7.1 & 2.01 & 1.33 & 48 & 23 & -51 \\
\hline
\end{tabular}

* GFR = glomerular filtration rate

$\dagger$ Values presented as mean \pm standard error. $(\mathrm{TF} / \mathrm{P})_{\mathrm{In}_{\mathrm{n}}}=$ tubular fluid to plasma inulin ratio.

saline diuresis; the average increase was $32 \%$.

The $(\mathrm{TF} / \mathrm{P})_{\text {In }}$ fell from an average value of 2.01 during the control periods to a value of 1.33 during the infusion of saline. The calculated per cent reabsorption fell from an average control level of $48 \%$ to a level of $23 \%$ during saline diuresis. In one experiment (no. 4) the rat was undergoing a mild diuresis (excreting $2 \%$ of filtered sodium) during control periods, and the per cent reabsorption in the proximal tubule was only $31 \%$; never-

TABLE II

Effect of saline infusions on intrinsic reabsorptive capacity and geometry of the proximal convoluted tubule*

\begin{tabular}{|c|c|c|c|c|c|c|}
\hline \multirow{2}{*}{$\begin{array}{l}\text { Rat } \\
\text { no. }\end{array}$} & \multicolumn{3}{|c|}{$\begin{array}{c}\text { Reabsorptive capacity } \dagger \\
\left(\mathrm{C} / \pi \mathrm{r}^{2}\right)\end{array}$} & \multicolumn{3}{|c|}{$\begin{array}{l}\text { Tubular volume per GFR } \\
\left(\pi r^{2} d / V o\right)\end{array}$} \\
\hline & Control & Saline & Change & Control & Saline & Change \\
\hline & $\sec ^{-1}$ & $\sec ^{-1}$ & $\%$ & $\mathrm{sec}$ & $\mathrm{sec}$ & $\%$ \\
\hline \multirow[t]{2}{*}{1} & 0.050 & 0.028 & -44 & 10.7 & 7.8 & -27 \\
\hline & \pm 0.005 & \pm 0.006 & & \pm 0.4 & \pm 0.4 & \\
\hline \multirow[t]{2}{*}{2} & 0.065 & 0.062 & -5 & 8.5 & 5.2 & -39 \\
\hline & \pm 0.002 & \pm 0.006 & & \pm 0.3 & \pm 0.3 & \\
\hline \multirow[t]{2}{*}{3} & 0.067 & 0.042 & -37 & 8.2 & 7.5 & -8 \\
\hline & \pm 0.003 & \pm 0.002 & & \pm 0.3 & \pm 0.4 & \\
\hline \multirow[t]{2}{*}{4} & 0.048 & 0.036 & -25 & 6.5 & 4.6 & -29 \\
\hline & \pm 0.007 & \pm 0.006 & & \pm 0.7 & \pm 0.3 & \\
\hline \multirow[t]{2}{*}{5} & 0.067 & 0.038 & -45 & 6.9 & 5.4 & -22 \\
\hline & \pm 0.004 & \pm 0.003 & & \pm 0.5 & \pm 0.3 & \\
\hline \multirow[t]{2}{*}{6} & 0.056 & 0.032 & -43 & 9.7 & 6.8 & -30 \\
\hline & \pm 0.007 & \pm 0.006 & & \pm 1.0 & \pm 0.2 & \\
\hline Average & 0.059 & 0.041 & -33 & & & -26 \\
\hline
\end{tabular}

* Values presented as mean \pm standard error.

+ Calculated from (TF/P) In and transit time values summarized in Table I, with Equation 3 in the text.

\pm Calculated by means of Equation 2 in the text. The units of this term are milliliters per milliliter per second, which reduces to seconds. theless, when saline was infused, excretion rose and proximal reabsorption fell to $16 \%$.

In association with the suppression of proximal reabsorption, transit time decreased significantly in every experiment. The transit time, which averaged 11.7 seconds during the control periods, fell to 7.1 seconds during saline diuresis. In rat no. 4 , which was mildly diuretic during the control period and had the lowest per cent reabsorption $(31 \%)$, the average control transit time of 7.9 seconds was significantly lower than that in the other animals. Nevertheless, the transit time in this animal shortened still further when saline was infused.

The effect of saline infusions on the intrinsic reabsorptive capacity was examined by calculating $\mathrm{C} / \pi \mathrm{r}^{2}$ for each pair of simultaneously measured $(\mathrm{TF} / \mathrm{P})_{\text {In }}$ and $\mathrm{T}$, with Equation 3. As shown in Table II, the average value for $\mathrm{C} / \pi \mathrm{r}^{2}$ was 0.059 second $^{-1}$ during control periods and 0.041 second $^{-1}$ during saline diuresis. The value for $\mathrm{C} / \pi \mathrm{r}^{2}$ decreased in all of the experiments except no. 2 ; the average decrease was $33 \%$.

During saline diuresis the kidney swelled, and the tubules appeared dilated. Photographs of the surface of the kidney before and during saline diuresis demonstrated that proximal tubular volume increased an average of $35 \%$. The effect of changes in tubular volume on fractional reabsorption, however, cannot be ascertained without relating tubular volume to the GFR in that nephron. 
The relation of tubular volume to GFR cannot be determined directly, since GFR per nephron was not measured and it cannot be assumed that the GFR in the superficial nephrons sampled by micropuncture was changing proportionately to the over-all GFR (9). However, the role of altered tubular volume in saline diuresis can be estimated very precisely by calculating $\pi \mathrm{r}^{2} \mathrm{~d} / \mathrm{Vo}$ for each pair of $(\mathrm{TF} / \mathrm{P})_{\text {In }}$ and transit time measurements. The value of $\pi r^{2} d /$ Vo was obtained by substituting the calculated values of $\mathrm{C} / \pi \mathrm{r}^{2}$ (Table II) into Equation 2. As shown in the last column of Table II, $\pi \mathrm{r}^{2} \mathrm{~d} /$ Vo decreased in every experiment except no. 3. The average decrease was $26 \%$ : This indicates that, although the proximal tubules dilated during saline diuresis, tubular volume did not increase proportionately to the rise in the GFR in the superficial nephrons.

In a second series of experiments the intrinsic reabsorptive capacity was measured directly with the shrinking-drop technique. The over-all response of these animals to the saline infusions was virtually identical to that seen in the first group of animals; GFR rose $33 \%$, sodium excretion increased to an average of $13 \%$ of the filtered sodium, and transit time decreased from a control value of 12 seconds to a diuretic value of 7 seconds. In the shrinking-drop measurements the average time $\left(t_{1}\right)$ required to reabsorb $50 \%$ of the injected column of isotonic saline was 10.6 seconds in control periods and increased to 15.3 seconds after the infusion of saline (Table III).
TABLE III

\begin{tabular}{|c|c|c|c|c|c|}
\hline \multirow{2}{*}{$\begin{array}{l}\text { Rat } \\
\text { no. }\end{array}$} & \multicolumn{2}{|c|}{ Reabsorptive $t_{\frac{1}{2}} *$} & \multicolumn{3}{|c|}{$\begin{array}{c}\text { Reabsorptive capacity } \\
\left(\mathrm{C} / \pi \mathrm{r}^{2}\right) \dagger\end{array}$} \\
\hline & Control & Saline & Control & Saline & Change \\
\hline & $\sec$ & sec & $\sec ^{-1}$ & $\sec ^{-1}$ & $\%$ \\
\hline 7 & $11.2 \pm 0.4$ & $14.7 \pm 0.6$ & 0.062 & 0.047 & -24 \\
\hline 8 & $9.4 \pm 0.6$ & $14.2 \pm 0.7$ & 0.074 & 0.049 & -34 \\
\hline 9 & $9.9 \pm 0.5$ & $15.3 \pm 0.8$ & 0.070 & 0.045 & -36 \\
\hline 10 & $12.0 \pm 1.0$ & $17.5 \pm 1.2$ & 0.058 & 0.040 & -31 \\
\hline 11 & $9.2 \pm 0.6$ & $11.9 \pm 0.5$ & 0.075 & 0.058 & -23 \\
\hline 12 & $12.6 \pm 0.8$ & $14.9 \pm 0.7$ & 0.055 & 0.046 & -16 \\
\hline 13 & $10.9 \pm 0.7$ & $14.7 \pm 0.4$ & 0.064 & 0.047 & -28 \\
\hline 14 & $10.1 \pm 0.5$ & $20.0 \pm 1.5$ & 0.069 & 0.035 & -50 \\
\hline 15 & $10.6 \pm 0.6$ & $15.0 \pm 0.5$ & 0.065 & 0.046 & -29 \\
\hline 16 & $10.0 \pm 0.6$ & $15.3 \pm 1.1$ & 0.069 & 0.045 & -35 \\
\hline Average & 10.6 & 15.3 & 0.066 & 0.046 & -31 \\
\hline
\end{tabular}

* Values presented as mean \pm standard error.

$\dagger$ Calculated from the expression, $C / \pi \mathrm{r}^{2}=0.693 / \mathrm{t}_{\frac{1}{3}}$ (Equation 4 in the text).

The average $C / \pi r^{2}$ was 0.066 second $^{-1}$ during the control periods and fell to 0.046 second $^{-1}$ during saline diuresis, for an average decrease of $31 \%$ (Table III). The five animals given DOCA responded in similar fashion to those not receiving DOCA; transit time shortened, and $\mathrm{C} / \pi \mathrm{r}^{2}$ decreased approximately $28 \%$ after the infusion of saline. Thus, both the absolute values for $C / \pi r^{2}$ and the per cent decrease during saline diuresis obtained directly by the shrinking-drop technique agree very closely with those calculated indirectly from the transit time and $(T F / P)_{\text {In }}$ in the freeflow experiments (Table II). Landwehr, Klose,

TABLE IV

Effect of lowering GFR by aortic constriction on the response of the intrinsic reabsorptive capacity and tubular geometry to saline infusions

\begin{tabular}{|c|c|c|c|c|c|c|c|}
\hline \multirow{2}{*}{$\begin{array}{l}\text { Rat } \\
\text { no. }\end{array}$} & \multirow[b]{2}{*}{ Procedure } & \multirow[b]{2}{*}{ GFR } & \multicolumn{2}{|c|}{ Shrinking-drop measurements } & \multirow{2}{*}{$\underset{\text { time }}{\text { Transit }}$} & \multirow{2}{*}{$\begin{array}{l}\text { Calculated } \\
(\mathrm{TF} / \mathrm{P})_{\text {In }} \dagger\end{array}$} & \multirow{2}{*}{$\begin{array}{l}\text { Tubular } \\
\text { volume } \\
\text { per GFR } \ddagger \\
\left(\pi \mathrm{r}^{2} \mathrm{~d} / \mathrm{Vo}\right)\end{array}$} \\
\hline & & & $t_{3}^{*}$ & $\mathrm{C} / \pi \mathrm{r}^{2}$ & & & \\
\hline & & $\mathrm{ml} / \min / \mathrm{kg}$ & $\sec$ & $\sec ^{-1}$ & sec & & $\sec$ \\
\hline 17 & $\begin{array}{l}\text { Control } \\
\text { Saline } \\
\text { Saline + aortic constriction }\end{array}$ & $\begin{array}{l}7.3 \\
9.5 \\
7.2\end{array}$ & $\begin{array}{r}8.7 \pm 0.5 \\
11.7 \pm 0.7 \\
12.0 \pm 0.4\end{array}$ & $\begin{array}{l}0.080 \\
0.059 \\
0.058\end{array}$ & $\begin{array}{r}10.5 \\
6.5 \\
6.2\end{array}$ & $\begin{array}{l}2.31 \\
1.47 \\
1.43\end{array}$ & $\begin{array}{l}7.1 \\
5.4 \\
5.2\end{array}$ \\
\hline 18 & $\begin{array}{l}\text { Control } \\
\text { Saline } \\
\text { Saline + aortic constriction }\end{array}$ & $\begin{array}{l}6.3 \\
8.2 \\
5.1\end{array}$ & $\begin{array}{r}9.6 \pm 0.6 \\
13.0 \pm 0.7 \\
13.6 \pm 0.8\end{array}$ & $\begin{array}{l}0.073 \\
0.053 \\
0.051\end{array}$ & $\begin{array}{r}11.0 \\
7.1 \\
7.0\end{array}$ & $\begin{array}{l}2.23 \\
1.46 \\
1.43\end{array}$ & $\begin{array}{l}7.5 \\
6.0 \\
5.9\end{array}$ \\
\hline 19 & $\begin{array}{l}\text { Control } \\
\text { Saline } \\
\text { Saline + aortic constriction }\end{array}$ & $\begin{array}{l}7.9 \\
9.9 \\
7.3\end{array}$ & $\begin{array}{l}10.5 \pm 0.7 \\
15.5 \pm 0.6 \\
16.1 \pm 0.8\end{array}$ & $\begin{array}{l}0.066 \\
0.045 \\
0.043\end{array}$ & $\begin{array}{r}11.4 \\
6.5 \\
7.0\end{array}$ & $\begin{array}{l}2.12 \\
1.34 \\
1.36\end{array}$ & $\begin{array}{l}8.0 \\
5.6 \\
6.0\end{array}$ \\
\hline
\end{tabular}

* Values presented as mean \pm standard error.

$\dagger$ Calculated from $\mathrm{C} / \pi \mathrm{r}^{2}$ and transit time, with Equation 3 in the text.

\$ Calculated by means of Equation 2 in the text. 
TABLE V

Effect of furosemide on transit time, fractional reabsorption, intrinsic reabsorptive capacity, and geometry of the proximal convoluted tubule

\begin{tabular}{|c|c|c|c|c|c|c|c|c|c|c|c|c|c|c|c|}
\hline \multirow[b]{2}{*}{$\begin{array}{l}\text { Rat } \\
\text { no. }\end{array}$} & \multicolumn{2}{|c|}{$\begin{array}{l}\text { Sodium } \\
\text { excretion } \\
\text { (\% of } \\
\text { filtered) }\end{array}$} & \multicolumn{3}{|c|}{ GFR } & \multicolumn{2}{|c|}{ Transit time } & \multicolumn{2}{|c|}{$(\mathrm{TF} / \mathrm{P})_{\mathrm{In}} *$} & \multicolumn{3}{|c|}{$\begin{array}{l}\text { Reabsorptive capacity } \dagger \\
\left(\mathrm{C} / \pi \mathrm{r}^{2}\right)\end{array}$} & \multicolumn{3}{|c|}{$\begin{array}{c}\text { Tubular volume per } \\
\text { GFR } \\
\left(\pi r^{2} \mathrm{~d} / \mathrm{No}^{ \pm}\right)\end{array}$} \\
\hline & $\begin{array}{l}\text { Con- } \\
\text { trol }\end{array}$ & $\begin{array}{l}\text { Furo- } \\
\text { semide }\end{array}$ & $\begin{array}{l}\text { Con- } \\
\text { trol }\end{array}$ & $\begin{array}{l}\text { Furo- } \\
\text { semide }\end{array}$ & Change & $\begin{array}{l}\text { Con- } \\
\text { trol }\end{array}$ & $\begin{array}{l}\text { Furo- } \\
\text { semide }\end{array}$ & Control & $\begin{array}{l}\text { Furo- } \\
\text { semide }\end{array}$ & Control & $\begin{array}{l}\text { Furo- } \\
\text { semide }\end{array}$ & Change & $\begin{array}{l}\text { Con- } \\
\text { trol }\end{array}$ & $\begin{array}{l}\text { Furo- } \\
\text { semide }\end{array}$ & Change \\
\hline & $\%$ & $\%$ & $\begin{array}{c}\mathrm{ml} / \mathrm{min} / \\
\mathrm{kg}\end{array}$ & $\begin{array}{c}m l / \\
\min / k g\end{array}$ & $\%$ & $\sec$ & $\sec$ & & & $\sec ^{-1}$ & $\sec ^{-1}$ & $\%$ & $\sec$ & $\mathrm{sec}$ & $\%$ \\
\hline 22 & 2 & 40 & 4.7 & 5.2 & +11 & 9.8 & 12.4 & $\begin{array}{r}1.96 \\
\pm 0.08\end{array}$ & $\begin{array}{r}1.99 \\
\pm 0.11\end{array}$ & 0.068 & 0.055 & -20 & 7.2 & 9.1 & +26 \\
\hline 23 & 0.4 & 27 & 10.6 & 7.3 & -31 & 9.6 & 13.5 & $\begin{array}{r}2.49 \\
\pm 0.19\end{array}$ & $\begin{array}{r}2.34 \\
\pm 0.16\end{array}$ & 0.095 & 0.063 & -34 & 5.9 & 9.1 & +54 \\
\hline 24 & 1 & 40 & 5.1 & 4.6 & -10 & 9.5 & 15.5 & $\begin{array}{r}1.72 \\
\pm 0.09\end{array}$ & $\begin{array}{r}1.96 \\
\pm 0.12\end{array}$ & 0.057 & 0.043 & -24 & 7.4 & 11.4 & +54 \\
\hline 25 & 0.2 & 34 & 6.6 & 5.7 & -13 & 13.5 & 20.0 & $\begin{array}{r}2.67 \\
\pm 0.04\end{array}$ & $\begin{array}{r}1.98 \\
\pm 0.11\end{array}$ & 0.072 & 0.034 & -53 & 8.6 & 14.7 & +71 \\
\hline 26 & 0.7 & 38 & 5.0 & 4.9 & -2 & 10.9 & 22.9 & $\begin{array}{r}2.29 \\
\pm 0.07\end{array}$ & $\begin{array}{r}2.00 \\
\pm 0.13\end{array}$ & 0.091 & 0.031 & -65 & 6.2 & 16.1 & +160 \\
\hline 27 & 0.5 & 28 & 9.4 & 8.8 & -6 & 11.7 & 19.5 & $\begin{array}{r}1.99 \\
\pm 0.09\end{array}$ & $\begin{array}{r}1.87 \\
\pm 0.11\end{array}$ & 0.059 & 0.032 & -46 & 8.5 & 14.3 & +69 \\
\hline 28 & 0.3 & 32 & 6.5 & 7.0 & +8 & 12.0 & 18.7 & $\begin{array}{r}2.15 \\
\pm 0.12\end{array}$ & $\begin{array}{r}2.20 \\
\pm 0.13\end{array}$ & 0.064 & 0.042 & -34 & 8.3 & 13.1 & +58 \\
\hline Average & & 34 & & & -6 & 11.0 & 17.5 & 2.20 & 2.05 & 0.072 & 0.043 & -39 & & & +70 \\
\hline
\end{tabular}

* Values presented as mean \pm standard error.

Calculated from (TF/P) In and transit time values, with Equation 3 in the text.

$\ddagger$ Calculated by means of Equation 2 in the text.

and Giebisch (10) have also observed that saline infusions depress $C / \pi r^{2}$.

To determine whether the changes in intrinsic reabsorptive capacity might be related to the observed increase in GFR, we examined the effect of lowering GFR during saline diuresis on $C / \pi r^{2}$, as measured with the shrinking-drop technique. The results of three experiments are shown in Table IV. Saline diuresis increased GFR by approximately $30 \%$, shortened transit time, and depressed $\mathrm{C} / \pi \mathrm{r}^{2}$ by approximately $30 \%$. The average calculated $(\mathrm{TF} / \mathrm{P})_{\text {In }}$ fell from 2.2 to 1.4 , and the calculated $\pi \mathrm{r}^{2} \mathrm{~d} / \mathrm{Vo}$ decreased by $25 \%$. The saline infusions were then continued, and the aorta was constricted above the renal arteries. In one experiment (no. 17) GFR fell back to the control level; in the other two, GFR fell below the control values. Despite this reduction in GFR, the values for $C / \pi r^{2}$, transit time, $(T F / P)_{I n}$, and $\pi \mathrm{r}^{2} \mathrm{~d} /$ Vo remained the same as during saline diuresis alone and did not return to their control level. Thus, the changes induced by saline diuresis are unrelated to the rise in GFR and persist after the elevated GFR is reduced back to or below control levels.

Expansion of ECF volume appears to induce a diuresis by both inhibiting the intrinsic reabsorptive capacity and reducing the ratio of tubular volume to GFR. For purposes of comparison, the effects of a pure inhibitor (furosemide) of reabsorption were examined; presumably such an agent might be anticipated to inhibit intrinsic reabsorptive capacity without reducing the ratio of tubular volume to GFR. Furosemide proved to be a very potent inhibitor; $\mathrm{C} / \pi \mathrm{r}^{2}$ measured with the shrinking-drop technique was reduced from a control value of 0.069 second $^{-1}$ to 0.041 second $^{-1}$, a decrease of $40 \%$. As shown in Table V, administration of furosemide induced a marked natriuresis, with approximately $34 \%$ of the filtered sodium excreted. The GFR rose slightly in two, fell moderately in one, and diminished slightly in four experiments; the average change in GFR was a decrease of $6 \%$. As was noted in saline diuresis, the kidney swelled and proximal tubular volume increased by approximately $40 \%$. In contrast to saline diuresis, however, the transit time was prolonged in every experiment, increasing from an average of 11.0 to 17.5 seconds. Despite the marked inhibition of intrinsic reabsorptive capacity, as demonstrated in the shrinkingdrop experiments, there was no significant decrease in the $(\mathrm{TF} / \mathrm{P})_{\mathrm{In}}$, and consequently no change in the per cent of filtrate reabsorbed in the proximal tubule. The value of $\mathrm{C} / \pi \mathrm{r}^{2}$ calculated from the paired $(T F / P)_{\text {In }}$ and transit time mea- 
surements was decreased by $39 \%$, confirming the shrinking-drop measurements. The calculated $\pi \mathrm{r}^{2} \mathrm{~d} /$ Vo rose by an average of $70 \%$.

\section{Discussion}

Previous studies $(1,3,11)$ have shown that the fraction of glomerular filtrate reabsorbed in the proximal convoluted tubule remains constant when the GFR is reduced by constricting the aorta above the renal arteries. This process of precisely readjusting reabsorption to changes in GFR, so as to maintain a constant relationship between the two, has been termed "glomerulotubular balance." The present experiments, however, confirm the observations of Dirks and associates (1) and of Cortney, Mylle, Lassiter, and Gottschalk (2) that expansion of ECF volume with isotonic saline alters the relation between proximal reabsorption and GFR and thus diminishes fractional reabsorption. Although GFR rose in every experiment after the infusion of saline, the fall in fractional reabsorption cannot be attributed to the elevation in GFR. It has been unequivocally shown by Dirks and associates (1) and by us ( 3 ) that when the rise in GFR produced by saline infusion is prevented by aortic constriction, fractional reabsorption remains depressed to the same level as is observed in saline diuresis without aortic constriction, where GFR is elevated. Therefore, some mechanism other than an increased GFR must be responsible for the diminished fractional reabsorption during saline diuresis. Moreover, on the basis of the aortic constriction experiments, it should be emphasized that the infusion of saline has only altered the relation between reabsorption and GFR (i.e., reduced fractional reabsorption) and has not disrupted the process of glomerulotubular balance. The effect of volume expansion is simply to reset the level at which the basic process of glomerulotubular balance stabilizes fractional reabsorption.

In previous studies on the mechanism of glomerulotubular balance $(3,4)$, we showed that fractional reabsorption in the proximal convoluted tubule is determined by the interactions among the reabsorptive rate constant per unit length of tubule (C), tubular volume $\left(\pi r^{2} d\right)$, and GFR per nephron (Vo). We found that when tubular volume was either decreased by constriction of the aorta above the renal arteries or elevated by rais- ing ureteral pressure, $\mathrm{C}$ changed proportionately; consequently, the ratio $\mathrm{C} / \pi \mathrm{r}^{2}$ remained constant (4). In addition we found that during aortic constriction both $\pi \mathrm{r}^{2} \mathrm{~d} / \mathrm{Vo}$ and fractional reabsorption remained constant, whereas in acute hydronephrosis the increase in $\pi \mathrm{r}^{2} \mathrm{~d} /$ Vo was associated with a proportionate rise in fractional reabsorption (3).

Fractional reabsorption, therefore, is determined by two control processes : first, the process or factors that determine the proportionality between $\mathrm{C}$ and $\pi \mathrm{r}^{2}$, and second, the factors that regulate the proportionality between Vo and $\pi r^{2} \mathrm{~d}$. Alteration in GFR by constricting the aorta while maintaining ECF volume constant results in a fall in absolute reabsorption but the maintenance of constant fractional reabsorption because the ratios $\mathrm{C} / \pi \mathrm{r}^{2}$ and $\pi \mathrm{r}^{2} \mathrm{~d} /$ Vo remain unchanged. In contrast, saline diuresis depresses both absolute and fractional reabsorption. Theoretically, this might result from inhibition of the intrinsic reabsorptive capacity, thus reducing the ratio $\mathrm{C} / \pi \mathrm{r}^{2}$, or by alteration of tubular geometry, so that the ratio $\pi \mathrm{r}^{2} \mathrm{~d} /$ Vo is lowered, or both.

It is clear from Tables II and III that saline infusions depress the intrinsic reabsorptive capacity of the proximal tubule. The decrease in $\mathrm{C} /$ $\pi \mathrm{r}^{2}$ during saline diuresis was $31 \%$ when measured directly (Table III) and 33\% when calculated (Table II). That the fall in intrinsic reabsorptive capacity was not caused by a rise in GFR is established by our previous studies on glomerulotubular balance (3) and more specifically by the present experiments in which GFR during saline diuresis was reduced by aortic constriction. This procedure returned the GFR to or below the control level, but had no effect on the diminished $\mathrm{C} / \pi \mathrm{r}^{2}$; during aortic constriction $\mathrm{C} / \pi \mathrm{r}^{2}$ was the same as during saline diuresis alone and was lower than during the control periods (Table IV). Thus, we concluded that expansion of ECF volume with saline inhibits the intrinsic reabsorptive capacity independent of any change in GFR.

The experiments with furosemide, however, clearly illustrate that inhibition of intrinsic reabsorptive capacity alone is not sufficient to reduce fractional reabsorption in the proximal convoluted tubule. As shown in Table $\mathrm{V}$, furosemide depressed $\mathrm{C} / \pi \mathrm{r}^{2}$ by approximately $40 \%$. Despite this marked inhibition of reabsorptive capacity, the 
$(\mathrm{TF} / \mathrm{P})_{\text {In }}$ was not significantly depressed. The failure of furosemide to decrease fractional reabsorption can be attributed in part to the fact that, secondary to the increased flow of fluid into the collecting ducts, intratubular pressure rose, causing dilatation of the proximal tubules. This resulted in a marked increase in the calculated $\pi \mathrm{r}^{2} \mathrm{~d} /$ Vo (Table V). As a result of tubular dilatation the linear flow of fluid is slowed and the transit time prolonged. A more important consequence of tubular dilatation is that reabsorption is accelerated (perhaps by opening pores in the luminal membrane and permitting more rapid accession of tubular fluid to active transport sites within the cell) sufficiently to counterbalance the specific inhibition of intrinsic reabsorptive capacity (4). The net effects of these changes are that the products of $\mathrm{C} / \pi \mathrm{r}^{2}$ and $\mathrm{T}$ and of $\mathrm{C} / \pi \mathrm{r}^{2}$ and $\pi \mathrm{r}^{2} \mathrm{~d} /$ Vo were more or less constant; consequently $(\mathrm{TF} / \mathrm{P})_{\text {In }}$ and fractional reabsorption (see Equations 2 and 3 ) were not significantly changed by furosemide.

These results with furosemide, therefore, demonstrate that inhibition of intrinsic reabsorptive capacity alone results only in tubular dilatation and slowing of the transit time and does not produce net suppression of proximal reabsorption. In sharp contrast to the results with furosemide, saline infusions, which inhibited intrinsic reabsorptive rate to approximately the same degree (30\% versus $40 \%$ inhibition), markedly depressed fractional reabsorption of filtrate in the proximal tubule. Expansion of ECF volume with saline, therefore, in addition to inhibiting intrinsic reabsorptive capacity, must have elicited some response that prevented the excessive tubular dilatation that occurs when only an inhibitor of intrinsic reabsorptive capacity, such as furosemide, is acting. This postulate is substantiated by the observation that during saline diuresis the transit time, rather than lengthening as in furosemide diuresis, actually became shorter.

The exact role of tubular volume in saline diuresis was determined by calculating the value of $\pi \mathrm{r}^{2} \mathrm{~d} / \mathrm{Vo}$ for each pair of $(\mathrm{TF} / \mathrm{P})_{\text {In }}$ and transit time measurements. As shown in the last column of Table II, $\pi r^{2} \mathrm{~d} / \mathrm{V}$ o was decreased by an average of $26 \%$. These results are in contrast to those obtained during furosemide diuresis, in which $\pi \mathrm{r}^{2} \mathrm{~d} / \mathrm{Vo}$ was markedly increased. It is clear, therefore, that one of the major differences between the effects of a pure inhibitor, such as furosemide, and saline infusion, is in the relation between tubular volume and GFR. One possible explanation for the difference is that GFR rose during saline diuresis and fell slightly after furosemide. The change in GFR, however, is clearly not the primary factor responsible for the altered $\pi \mathrm{r}^{2} \mathrm{~d} /$ Vo. For example, in rats no. 22 and 28 (Table V) GFR did not fall after furosemide but rose slightly; nevertheless $\pi r^{2} d / V o$ increased, as it did in those experiments in which GFR fell. More importantly, however, in saline diuresis, when GFR was reduced towards or below control levels by aortic constriction, the value for $\pi r^{2} d / V o$ remained low (Table IV). Consequently, the reduced $\pi r^{2} \mathrm{~d}$ /Vo during saline diuresis cannot be attributed simply to a failure of tubular volume to increase proportionately to the rise in GFR, but instead represents a major readjustment within the kidney so that, at any given level of GFR, tubular volume is reduced.

The results of our studies, therefore, indicate that two different processes contribute to the suppression of proximal reabsorption during saline diuresis: 1) inhibition of intrinsic reabsorptive capacity, and 2) reduction in tubular size relative to any given level of GFR. The observed 33\% decrease in intrinsic reabsorptive capacity, $\mathrm{C} / \pi \mathrm{r}^{2}$, and $26 \%$ decrease in relative tubular size, $\pi \mathrm{r}^{2} \mathrm{~d} /$ Vo, combined to depress fractional reabsorption by $51 \%$.

The factors responsible for inhibiting the intrinsic reabsorptive capacity are not known. The most likely possibility is the elaboration of some hormonal agent, probably extrarenal in origin. Cross-circulation experiments (12-14) have yielded suggestive, but not clear-cut, evidence for the existence of such a hormone. Organ ablation experiments (15), however, have failed to identify the site of production of such a natriuretic hormone.

The factors that regulate the relationship between tubular size and GFR are also poorly understood. The radius of an elastic cylinder, such as the proximal tubule, will be proportional to its elasticity and the difference between the intraluminal and interstitial pressures. Although direct measurements of intraluminal and peritubular capillary pressures reveal no pressure gradient, 
it is reasonable to assume that such a gradient does in fact exist, but that the gradient is simply smaller than the errors inherent in the pressure measurements.

Since the proximal tubule can change its volume in response to small variations in the transmural pressure gradient and can also change its reabsorptive rate proportionately to the alterations in tubular volume, it will exhibit some of the characteristics of an autoregulatory system. For example, if reabsorption decreases, perhaps due to the presence of an inhibitor, less fluid will enter the interstitium and more remain in the tubular lumen. Consequently, intraluminal pressure will rise, and interstitial pressure will fall, at least transiently. The tubule will then dilate, reabsorptive rate will increase proportionately to tubular volume, and a new steady state will be achieved in which reabsorption will be near normal, but the tubule will be dilated and tubular flow slowed. This probably accounts, at least in part, for the failure of furosemide to suppress fractional reabsorption. The autoregulatory characteristics of this system are such that neither a decrease nor increase in intrinsic reabsorptive capacity is likely to influence net proximal reabsorption appreciably unless there is also an additional factor that prevents the reciprocal change in tubular volume.

There are two other factors that might influence tubular volume independently of intrinsic reabsorptive factors: 1) peritubular colloid osmotic pressure (COP), and 2) blood flow into the peritubular capillaries relative to the GFR. For example, a rise in COP would facilitate the transfer of reabsorbate from the interstitium into the peritubular capillaries causing a transient fall in interstitial pressure, tubular dilatation, and augmented reabsorption. A fall in COP would have the reverse effect. This important role of COP affords some insight into the observations that raising serum albumin with infusions of hyperoncotic albumin prevents saline diuresis despite expansion of plasma volume (16-18).

Since COP is determined by the concentration of protein in arterial plasma and the volume of protein-free fluid removed at the glomerulus, any factor that alters the filtration fraction will change the postglomerular COP and will thus influence tubular volume. However, in addition to its effects on postglomerular COP, changes in filtration fraction will also influence tubular volume by changing postglomerular blood flow relative to the GFR. If, for example, GFR remained constant, while renal blood flow increased (i.e., reduced filtration fraction), peritubular hydrostatic pressures would be transiently elevated relative to the intratubular pressure, the tubule would be narrowed, and reabsorption would be proportionately reduced. Since filtration fraction diminishes in saline diuresis $(19,20)$, it is reasonable to conclude that the resultant fall in postglomerular COP and rise in postglomerular blood flow relative to the GFR contribute to the fall in tubular volume per unit GFR observed in the present studies.

The most likely cause for variations in filtration fraction during different physiologic and pathologic states is alterations in the resistance of the afferent and efferent arterioles, a rise in resistance causing an elevated filtration fraction and a fall in resistance resulting in a reduced filtration fraction. This hypothesis is consistent with the suggestion by Earley and Friedler (21) that renal vascular resistance plays a major role in the control of sodium reabsorption and is supported by the fact that blocking renal arteriolar tone with autonomic blocking agents (22-25) induces saline diuresis in normal animals and partially corrects the salt-retaining state in animals with either heart failure (26) or obstruction of the inferior vena cava above the liver (27). The factors controlling renal arteriolar resistance are not completely known, but presumably the activity of the autonomic system (principally sympathetic) and the level of circulating vasoactive substances (catecholamines, angiotensin) are of major importance. Although renal arteriolar resistance assumes the central role in this regulatory system, we recognize that changes in other physical parameters [blood viscosity, arterial blood pressure (21), resistance in Henle's loop, medullary tissue turgor] might also alter the relation between GFR and proximal tubular volume and thus influence sodium excretion.

\section{References}

1. Dirks, J. H., W. J. Cirksena, and R. W. Berliner. The effect of saline infusion on sodium reabsorp- 
tion by the proximal tubule of the dog. J. clin. Invest. $1965,44,1160$.

2. Cortney, M. A., M. Mylle, W. E. Lassiter, and C. W. Gottschalk. Renal tubular transport of water, solute, and PAH in rats loaded with isotonic saline. Amer. J. Physiol. 1965, 209, 1199.

3. Rector, F. C., Jr., F. P. Brunner, and D. W. Seldin. Mechanism of glomerulotubular balance. I. Effect of aortic constriction and elevated ureteropelvic pressure on glomerular filtration rate, fractional reabsorption, transit time, and tubular size in the rat. J. clin. Invest. 1966, 45, 590.

4. Brunner, F. P., F. C. Rector, Jr., and D. W. Seldin. Mechanism of glomerulotubular balance. II. Regulation of proximal tubular reabsorption by tubular volume, as studied by stopped-flow microperfusion. J. clin. Invest. 1966, 45, 603 .

5. Gertz, K. H. Transtubuläre Natriumchloridflüsse und Permeabilität für Nichtelektrolyte im proximalen und distalen Konvolut der Rattenniere. Pflügers Arch. ges. Physiol. 1963, 276, 336.

6. Gertz, K. H., J. A. Mangos, G. Braun, and H. D. Pagel. On the glomerular tubular balance in the rat kidney. Pflügers Arch. ges. Physiol. 1965, $285,360$.

7. Hilger, H. H., J. D. Klümper, and K. J. Ullrich. Wasserrückresorption und Ionentransport durch die Sammelrohrzellen der Säugetierniere. Pflügers Arch. ges. Physiol. 1958, 267, 218.

8. Davidson, W. D., and M. A. Sackner. Simplification of the anthrone method for the determination of inulin in clearance studies. J. Lab. clin. Med. 1963, 62, 351.

9. Barger, A. C. Renal hemodynamic factors in congestive heart failure. Proc. N. Y. Acad. Sci. 1966, in press.

10. Landwehr, D. M., R. M. Klose, and G. Giebisch. Micropuncture study of sodium reabsorption in saline-loaded rats. Fed. Proc. 1966, 25, 460.

11. Glabman, S., H. S. Aynedjian, and N. Bank. Micropuncture study of the effect of acute reductions in glomerular filtration rate on sodium and water reabsorption by the proximal tubules of the rat. J. clin. Invest. 1965, 44, 1410.

12. De Wardener, H. E., I. H. Mills, W. F. Clapham, and C. J. Hayter. Studies on the efferent mechanism of the sodium diuresis which follows the administration of intravenous saline in the dog. Clin. Sci. 1961, 21, 249.

13. Lichardus, B., and J. W. Pearce. Evidence for a humoral natriuretic factor released by blood volume expansion. Nature (Lond.) 1966, 209, 407.

14. Johnston, C. I., and J. O. Davis. Evidence from cross circulation studies for a humoral mechanism in the natriuresis of saline loading. Proc. Soc. exp. Biol. (N. Y.) 1966, 121, 1058.

15. Levinsky, N. G. Non-aldosterone influences on renal sodium transport. Proc. N. Y. Acad. Sci. 1966, in press.

16. Goodyer, A. V. N., E. R. Peterson, and A. S. Relman. Some effects of albumin infusions on renal function and electrolyte excretion in normal man. J. appl. Physiol. 1949, 1, 671.

17. Petersdorf, R. G., and L. G. Welt. The effect of an infusion of hyperoncotic albumin on the excretion of water and solutes. J. clin. Invest. 1953, 32, 283.

18. Welt, L. G., and J. Orloff. The effects of an increase in plasma volume on the metabolism and excretion of water and electrolytes by normal subjects. J. clin. Invest. 1951, 30, 751.

19. Wilson, J. R., Jr., and C. R. Harrison. Cardiovascular, renal, and general effects of large, rapid plasma infusions in convalescent men. J. clin. Invest. 1950, 29, 251.

20. Earley, L. E., and R. M. Friedler. Changes in renal blood flow and possibly the intrarenal distribution of blood during the natriuresis accompanying saline loading in the dog. J. clin. Invest. 1965, 44, 929.

21. Earley, L. E., and R. M. Friedler. The effects of combined renal vasodilatation and pressor agents on renal hemodynamics and the tubular reabsorption of sodium. J. clin. Invest. 1966, 45, 542.

22. Del Greco, F., A. C. Corcoran, and I. H. Page. Hyposthenuria and other renal effects of hexamethonium in the hydropenic anesthetized dog. J. Pharmacol. exp. Ther. 1956, 117, 434.

23. Gill, J. R., Jr., D. T. Mason, and F. C. Bartter. Adrenergic nervous system in sodium metabolism: effects of guanethidine and sodium-retaining steroids in normal man. J. clin. Invest. 1964, 43, 177.

24. Vander, A. J. Effects of acetylcholine, atropine, and physostigmine on renal function in the dog. Amer. J. Physiol. 1964, 206, 492.

25. Earley, L. E., and R. M. Friedler. Studies on the mechanism of natriuresis accompanying increased renal blood flow and its role in the renal response to extracellular volume expansion. J. clin. Invest. 1965, 44, 1857.

26. Barger, A. C., F. P. Muldowney, and M. R. Liebowitz. Role of the kidney in the pathogenesis of congestive heart failure. Circulation 1959, 20, 273.

27. Friedler, R. M., L. Belleau, and L. E. Earley. Hemodynamically induced reversal of the sodium retention resulting from acute superhepatic inferior vena caval constriction (abstract). J. clin. Invest. 1966, 45, 1009. 